\section{(6) OPEN ACCESS}

\title{
Low-intensity case management increases contact with primary care in recently released prisoners: a single-blinded, multisite, randomised controlled trial
}

\author{
Stuart A Kinner, ${ }^{1,2,3}$ Rosa Alati, ${ }^{4}$ Marie Longo, ${ }^{5}$ Matthew J Spittal, ${ }^{2}$ \\ Frances M Boyle, ${ }^{4}$ Gail M Williams, ${ }^{4}$ Nicholas G Lennox ${ }^{3}$
}

\begin{abstract}
- Additional material is published online only. To view please visit the journal online (http://dx.doi.org/10.1136/jech2015-206565)

${ }^{1}$ Griffith Criminology Institute \& Menzies Health Institute Queensland, Griffith University, Brisbane, Australia

${ }^{2}$ Melbourne School of

Population and Global Health, The University of Melbourne,

Melbourne, Australia ${ }^{3}$ Queensland Centre for Intellectual and Developmental Disability, Mater Research Institute-UQ, The University of Queensland, Brisbane, Australia

${ }^{4}$ School of Public Health, University of Queensland, Brisbane, Australia ${ }^{5}$ Drug and Alcohol Services South Australia, Adelaide, Australia
\end{abstract}

\section{Correspondence to}

Professor Stuart A Kinner, Griffith Criminology Institute \& Menzies Health Institute Queensland, Griffith University, 176 Messines Ridge Rd. Mt Gravatt, Brisbane, QLD 4122 Australia; s.kinner@griffith.edu.au

Received 27 August 2015 Revised 5 December 2015 Accepted 22 December 2015 Published Online First 19 January 2016

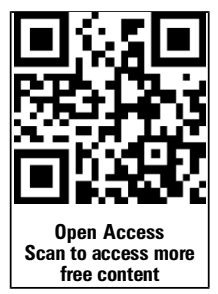

CrossMark

To cite: Kinner SA, Alati $\mathrm{R}$ Longo $\mathrm{M}$, et al. J Epidemiol Community Health

2016:70:683-688.

\section{ABSTRACT}

Background The world prison population is large and growing. Poor health outcomes after release from prison are common, but few programmes to improve health outcomes for ex-prisoners have been rigorously evaluated. The aim of this study was to evaluate the impact of individualised case management on contact with health services during the first 6 months postrelease.

Methods Single-blinded, randomised, controlled trial. Baseline assessment with $\mathrm{N}=1325$ adult prisoners in Queensland, Australia, within 6 weeks of expected release; follow-up interviews 1, 3 and 6 months postrelease. The intervention consisted of provision of a personalised booklet ('Passport') at the time of release, plus up to four brief telephone contacts in the first 4 weeks post-release.

Results Of 1179 eligible participants, 1003 (85\%) completed $\geq 1$ follow-up interview. In intention-to-treat analyses, $53 \%$ of the intervention group and $41 \%$ of the control group reported contacting a general practitioner (GP) at 1 month post-release (difference $=12 \%, 95 \% \mathrm{Cl} \%$ to $19 \%$ ). Similar effects were observed for GP contact at 3 months (difference $=9 \%, 95 \% \mathrm{Cl} 2 \%$ to $16 \%$ ) and 6 months (difference $=8 \%, 95 \% \mathrm{Cl} 1 \%$ to $15 \%$ ), and for mental health $(\mathrm{MH})$ service contact at 6 months post release (difference $=8 \%, 95 \% \mathrm{Cl} 3 \%$ to $14 \%$ ).

Conclusions Individualised case management in the month after release from prison increases usage of primary care and $\mathrm{MH}$ services in adult ex-prisoners for at least 6 months post-release. Given the poor health profile of ex-prisoners, there remains an urgent need to develop and rigorously evaluate interventions to increase health service contact in this profoundly marginalised population.

Trial registration number ACTRN12608000232336.

\section{INTRODUCTION}

More than 10 million people are incarcerated around the world on any given day. ${ }^{1}$ Prisoners are characterised by profound social disadvantage and a high prevalence of complex, chronic and often preventable health problems including substance dependence, mental disorder, communicable and non-communicable disease. ${ }^{2}{ }^{3}$ Prisoners also underutilise health services in the community, ${ }^{4}$ and at least in high-income countries, their health typically improves in custody where food and shelter are provided at no or low cost, illicit drugs are less readily available, and the threshold for access to healthcare is relatively low. ${ }^{5}$ Time in custody provides unique opportunities to screen for disease and initiate care, ${ }^{4}$ with the benefits potentially flowing to the wider community once prisoners are released. ${ }^{6}$

An estimated 30 million people are released from prisons each year, ${ }^{7}$ however, any health gains achieved in custody are typically lost soon after release. Those released from prison experience high rates of preventable morbidity ${ }^{8-10}$ and mortality, ${ }^{11} 12$ and are heavy users of expensive, tertiary healthcare services. ${ }^{13}{ }^{14}$ Some of these poor health outcomes are associated with an increased risk of recidivism. ${ }^{6}{ }^{15}$ Under-utilisation of preventive care post-release may be an important driver of these outcomes, ${ }^{16}$ however, interventions to coordinate and increase health service usage in ex-prisoners (so-called 'case management' interventions) are rarely evaluated. ${ }^{17}{ }^{18}$ In one quasi-randomised controlled trial (RCT) involving 725 prisoners in New York State, those in the intervention group reported more frequent contact with support services in the community, but were also more likely to be rearrested. ${ }^{19}$ In another study of 2391 prisoners in 14 US states, which used propensity score matching in an attempt to control for confounding by indication, case management was associated with increased receipt of health and social support services post-release. ${ }^{20}$ We are unaware of any randomised trials of this sort of intervention globally, or of any rigorous evaluations outside the USA.

The aim of this study was to evaluate the impact of a case management intervention for adult prisoners/ex-prisoners in Queensland, Australia, on contact with primary care, mental health $(\mathrm{MH})$ services, and alcohol and other drug (AOD) treatment services, in the first 6 months post-release.

\section{METHODS}

The full protocol for this trial has been published elsewhere. ${ }^{21}$

\section{Randomisation and masking}

The study design was a single-blinded, randomised controlled trial. Participants were blinded to treatment allocation. Randomisation was stratified by prison (and therefore by sex), prior prison history (yes/no) and indigenous status (indigenous/nonindigenous) using a coded list of random permutation blocks of size 4. Baseline data were collected in prison before randomisation and within 6 weeks of expected release from custody; follow-up telephone interviews occurred approximately 1, 3 and 6 months post-release. 
The study conformed to the principles embodied in the Declaration of Helsinki. ${ }^{22}$ It received approval from the University of Queensland's Behavioural and Social Sciences Ethical Review Committee and the Queensland Corrective Services (QCS) Research Committee, and was registered with the Australian New Zealand Clinical Trials Registry (ACTRN12608000232336).

\section{Participants}

Participants were sentenced adult prisoners from seven adult correctional centres in Queensland, Australia. Those eligible for participation expected to be released from custody within the succeeding 6 weeks (either full-time or on parole); were able to provide informed, written consent for participation; and (due to the high incidence of reincarceration) had not participated previously. Women were oversampled by a factor of 2 to ensure sufficient numbers for stratified analyses. Those on remand (pretrial) were excluded due to uncertainty regarding release.

\section{Procedures}

Baseline and randomisation

Potential participants were identified from prison records and approached by trained research staff not affiliated with the prison. Those expressing interest in the study were screened for eligibility, and for those deemed eligible, written informed consent was obtained. Baseline interviews were conducted in paper and pencil format in a private setting in the prison with only the participant and researcher present. To minimise literacy concerns, all questions were read aloud by the researcher. Data from the baseline interview were entered into a secure database that automatically randomised participants to the intervention or control group. Recruitment and baseline interviews occurred over a 2-year period from August 2008 to July 2010.

\section{Intervention}

The intervention consisted of two components. First, based on data collected during the baseline interview, participants in the intervention group received a personalised booklet ('Passport') at the time of release from prison. The Passport included three sections: (1) a step-by-step guide to key re-entry tasks such as securing accommodation and income, (2) a plain language and graphical summary of the participant's health status and treatment needs and (3) a list of relevant community services addressing health and psychosocial needs, tailored to the participant's demographic characteristics, health status and expected location post-release.

The second component of the intervention involved contacting participants by telephone on up to four occasions during the first 28 days post-release (ideally once a week). Intervention calls were delivered by trained staff, focused on basic health promotion and the identification of services to meet identified health and psychosocial needs, and were informed by principles of motivational interviewing. ${ }^{23}$

Participants in the control group received usual care, which may or may not have included transitional support provided by QCS. Both the intervention and the nature of usual care in this setting are described in greater detail elsewhere. ${ }^{24}$

\section{Evaluation}

Intervention calls to each participant ceased before follow-up interviews started. Follow-up telephone interviews were conducted by the same team of trained researchers and occurred approximately 1, 3 and 6 months post-release. For those who returned to custody during follow-up, follow-up interviews were completed either face-to-face or by telephone, depending on security considerations and the location of the prison.

\section{Measures}

Both the baseline and follow-up interviews covered demographic characteristics, community circumstances, physical health, $\mathrm{MH}$, substance use and other risk behaviours, and health-seeking behaviours. Current medications were obtained at all waves by self-report, and at baseline from an audit of prison medical records. ${ }^{25}$ During each follow-up interview participants reported whether or not they had seen a general practitioner (GP), $\mathrm{MH}$ service or AOD service in the community, since their last interview, and if so, on how many occasions. Baseline interviews typically took $60 \mathrm{~min}$ to complete, and follow-up interviews typically took 20-30 min to complete.

\section{Analysis}

The primary analysis was an intention-to-treat (ITT) analysis using two-sample tests of proportions, however, in anticipation of some intervention participants being uncontactable in the first 4 weeks post-release, we also undertook an a priori per-protocol (PP) analysis in which those in the intervention group who received no post-release intervention calls were excluded. We also undertook a priori sensitivity analyses excluding 'higher needs' participants: those with a history of prior imprisonment, those identifying as Indigenous, and those with a lifetime history of injecting drug use. ${ }^{21}$ In an additional, post hoc sensitivity analysis, we excluded follow-up interviews that were conducted in prison. All group differences are shown as absolute differences, with 95\% CI. All analyses were undertaken using Stata V.13.0. ${ }^{26}$

\section{Role of the funding source}

The sponsor of the study had no role in the study design, data collection, data analysis, data interpretation or writing of the report. The corresponding author had full access to all the data in the study, and had final responsibility for the decision to submit for publication.

\section{RESULTS}

We assessed 1976 participants for eligibility, of whom 1665 were eligible and 1325 enrolled in the study, giving a recruitment fraction of $80 \%$ (figure 1). Participants were similar to all other adults released from custody in Queensland during the 2-year period of study recruitment, except that females were intentionally oversampled. ${ }^{21}$ One hundred and forty-three participants were not released within 6 weeks of baseline interview, and 3 participants were exited after receiving materials intended for the other arm of the trial in error, leaving 1179 eligible participants. Of these, 1003 (85\%) completed at least one follow-up interview. Follow-up fractions were similar in the control group $(n=487$, $83 \%)$ and the intervention group $(n=516,87 \%)$.

After randomisation, participants in the intervention (IX) and control (TAU) groups were similar with respect to demographic characteristics, prison history and health status (table 1).

The effect of the intervention on health service usage at each follow-up is summarised in table 2. Those in the intervention group were significantly more likely to report contacting a GP 1,3 and 6 months post-release (difference 12\%, 9\% and $8 \%$, respectively), and to report contacting a $\mathrm{MH}$ service at 6 months post-release (difference 8\%). All other group differences were in the expected direction but were not significant at $\mathrm{p}<0.05$.

Owing to delayed release and difficulty in establishing contact in the immediate post-release period, $23 \%$ of the intervention 


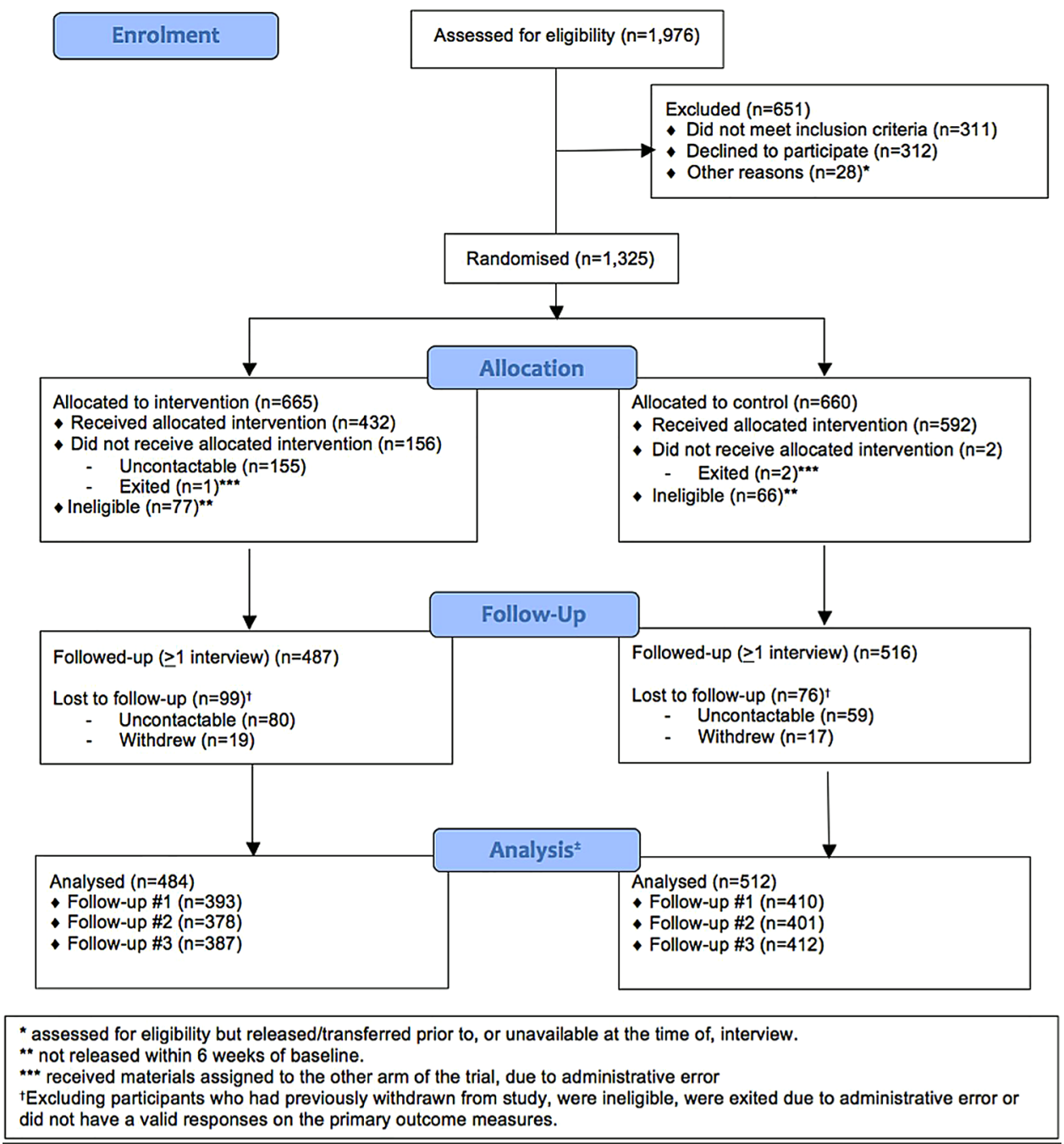

Figure 1 CONSORT diagram.

group $(n=155)$ did not receive any post-release intervention telephone calls. We undertook an a priori PP analysis excluding these participants. The effect on health service usage did not change substantively (table 3 ).

We also undertook a priori sensitivity analyses excluding participants with a history of prior imprisonment, those identifying as indigenous, and those with a lifetime history of injecting drug use. In a post hoc sensitivity analysis, we excluded follow-up interviews completed in prison. In each case, the results did not change substantively, except that when participants with a history of injecting drug use were excluded, the intervention had no significant effect on contact with a GP at any evaluated time point. Among those with no history of injecting drug use, those in the intervention group were significantly more likely to report contact with an $\mathrm{MH}$ service at 6 months post-release (difference $=9 \%, 95 \%$ CI $1 \%$ to $16 \%$ ) (see online supplementary material).

Finally, we observed a dose-response relationship between number of intervention calls and proportion of participants contacting a GP at 1 month post-release (figure 2). Those who received four intervention calls were significantly more likely than those who received only one intervention call to contact a GP at 1 month post-release $(\mathrm{OR}=2.45,95 \%$ CI 1.06 to 5.66$)$. A similar pattern was evident for GP contact at 3 and 6 months post-release, and for $\mathrm{MH}$ service contact at 6 months postrelease (see online supplementary material).

\section{DISCUSSION}

In a randomised controlled trial design, we found that a brief, low-intensity case management intervention delivered in the first 4 weeks after release from prison significantly increased contact with primary care for at least 6 months post-release. The intervention also increased contact with $\mathrm{MH}$ services at 6 months post-release, although group differences at earlier time points were not significant. The intervention had no significant effect on contact with AOD services at any evaluated time point.

Ours is the first study to show an effect of case management for people released from prison, while using a randomised design. Highlighting the challenges in retaining this population in care, more than a quarter of the intervention group received no intervention calls in the first 4 weeks post-release, however, the results of PP analyses were consistent with those of intention-to-treat analyses. The effects were also robust to sensitivity analyses, except that the intervention did not significantly increase contact with primary care in ex-prisoners with no history of injecting drug use. The reasons for this are unclear but, if replicable, are encouraging given evidence of particularly poor health outcomes in ex-prisoners with a history of injecting drug use. ${ }^{2}{ }^{9}$ We observed a dose-response relationship between number of intervention calls and contact with primary care at each time point, and with $\mathrm{MH}$ service contact at 6 months, providing further evidence of a causal relationship between the intervention and health service contact. 
Table 1 Characteristics of participants at baseline, by intervention group

\begin{tabular}{|c|c|c|c|c|}
\hline & $\mathrm{N}$ & $\begin{array}{l}\text { IX (\%) } \\
(n=665)\end{array}$ & $\begin{array}{l}\text { TAU (\%) } \\
(n=660)\end{array}$ & $\begin{array}{l}\mathrm{p} \\
\text { Value* }\end{array}$ \\
\hline Mean age in years (SD) & 1325 & $32.7(11.3)$ & $32.8(10.9)$ & 0.86 \\
\hline Male & 1325 & 78.5 & 79.2 & 0.74 \\
\hline Indigenous & 1325 & 25.4 & 25.6 & 0.94 \\
\hline Married/de facto & 1325 & 34.9 & 34.2 & 0.76 \\
\hline$<10$ years of schooling & 1325 & 41.4 & 45.3 & 0.15 \\
\hline Unemployed before prison & 1325 & 52.6 & 53.5 & 0.76 \\
\hline $\begin{array}{l}\text { Unstable accommodation } \\
\text { before prison }\end{array}$ & 1320 & 17.5 & 16.0 & 0.46 \\
\hline Prior prison admission & 1325 & 67.4 & 67.0 & 0.88 \\
\hline $\begin{array}{l}\text { Median days in prison } \\
\text { (SD) }\end{array}$ & 1325 & $309.8(549.7)$ & $321.1(567.0)$ & 0.71 \\
\hline $\begin{array}{l}\text { Hepatitis C antibody } \\
\text { positivet }\end{array}$ & 1246 & 17.8 & 14.4 & 0.10 \\
\hline Taking $\geq 1$ medicationt & 1231 & 48.3 & 43.6 & 0.09 \\
\hline $\begin{array}{l}\text { High/very high } \\
\text { psychological distress }\end{array}$ & 1320 & 27.8 & 24.2 & 0.13 \\
\hline $\begin{array}{l}\text { Lifetime diagnosis of } \\
\text { mental illness }\end{array}$ & 1324 & 45.3 & 41.6 & 0.18 \\
\hline $\begin{array}{l}\text { Lifetime injecting drug use } \\
\text { history }\end{array}$ & 1322 & 57.2 & 54.3 & 0.30 \\
\hline Risky cannabis use§ & 1324 & 47.1 & 45.6 & 0.58 \\
\hline Risky heroin use§ & 1322 & 17.2 & 17.9 & 0.73 \\
\hline $\begin{array}{l}\text { Risky methamphetamine } \\
\text { use§ }\end{array}$ & 1323 & 38.6 & 37.9 & 0.82 \\
\hline Risky alcohol useף & 1296 & 61.6 & 61.4 & 0.93 \\
\hline Current tobacco smoker & 1324 & 80.1 & 76.4 & 0.10 \\
\hline $\begin{array}{l}\text { Received QCS transitional } \\
\text { support }\end{array}$ & 1324 & 42.5 & 41.7 & 0.15 \\
\hline $\begin{array}{l}\text { Correctional supervision } \\
\text { post-release }\end{array}$ & 1324 & 59.2 & 61.1 & 0.49 \\
\hline
\end{tabular}

*Independent samples $t$ test for continuous variables, $\chi^{2}$ test for categorical variables. tFrom medical records.

$¥$ According to Kessler Psychological Distress Scale (K10).

$\S$ According to Alcohol, Smoking and Substance Use Involvement Screening Test (ASSIST).

ๆAccording to Alcohol Use Disorders Identification Test (AUDIT).

IX, intervention; QCS, Queensland Corrective Services; TAU, treatment as usual.

Given the high prevalence of mental disorder in prison populations, ${ }^{27} 28$ it is encouraging that the intervention increased contact with $\mathrm{MH}$ services, although this difference was only significant at the 6-month follow-up. One possible explanation for this delayed effect is that participants were referred to $\mathrm{MH}$ services via primary care: the Australian government provides subsidies for up to 10 sessions with a $\mathrm{MH}$ practitioner per annum, when the patient is referred by a GP. The scheme has been shown to improve access to $\mathrm{MH}$ care among patients with high levels of need. ${ }^{29}$ To the extent that this is the case, it highlights a pivotal role for primary care as a pathway into more specialised care for ex-prisoners. ${ }^{30}$

Substance misuse is a key health concern for ex-prisoners, ${ }^{31}$ but the intervention did not significantly increase contact with AOD treatment services at any evaluated time point. The reasons for this require further exploration, but may include high barriers for entry into AOD treatment including stigma, financial costs, restrictive eligibility criteria and long waiting lists for treatment places. $^{32}$ In countries where the threshold for accessing AOD treatment is lower, the effect of case management on AOD service usage may be greater.

The primary outcome of this trial was contact with health services, however, the ultimate goal of increasing contact with health services is to improve health outcomes. ${ }^{21}$ Our study was not designed to measure changes in health outcomes, and given the population sampling frame and consequent heterogeneity in health-related needs, secondary analyses focusing on health outcomes in this cohort would be exploratory. Particularly for vulnerable populations with complex needs, health service contact is unlikely to be a panacea, and increased contact with health services is not always associated with better health outcomes. ${ }^{33}$ Equally important is the nature and quality of those contacts, and there is growing evidence that at least in primary care settings, patients in marginalised communities tend to experience shorter consultations, less health promotion, and a greater focus on the prescription of (sometimes unaffordable) medications. ${ }^{34}$ Contact with health services is in many cases a necessary but not sufficient condition for improved health outcomes.

In this study, $55 \%$ of eligible participants contacted a GP, $20 \%$ contacted a $\mathrm{MH}$ service, and $23 \%$ contacted an AOD treatment service within 6 months of release from prison. That such a large proportion of ex-prisoners contacted a GP is encouraging, given the critical role of primary care in reducing health inequity by promoting access to needed services and early management of health problems. ${ }^{35}$ As well as shaping health service delivery and, potentially, health outcomes for people released from prison, ${ }^{36}$ increased primary care engagement may also reduce usage of acute and tertiary health services. $^{36}$ In countries without universal healthcare, such as the USA, healthcare usage in ex-prisoners is likely to be considerably lower than in Australia, although recent expansion of health insurance eligibility in the USA may dramatically improve access to healthcare for disadvantaged populations such as ex-prisoners. ${ }^{37}$ Barriers to care are not only financial, and our study shows that even in the context of universal health insurance, a simple, low-intensity intervention can increase usage of health services.

This is the first ever randomised trial of a case management intervention for ex-prisoners. The population sampling frame, large sample size and good follow-up are strengths of the study.

Table 2 Percentage reporting health service contact at follow-up, by group (ITT analyses)

\begin{tabular}{|c|c|c|c|c|c|c|c|c|c|}
\hline & \multicolumn{3}{|l|}{1 Month } & \multicolumn{3}{|l|}{3 Months } & \multicolumn{3}{|l|}{6 Months } \\
\hline & IX \% (n) & TAU \% (n) & Difference $(95 \% \mathrm{Cl})$ & IX (\%) & TAU (\%) & Difference $(95 \% \mathrm{Cl})$ & IX (\%) & TAU (\%) & Difference $(95 \% \mathrm{CI})$ \\
\hline \multicolumn{10}{|c|}{ Service type } \\
\hline GP & $53(393)$ & $41(410)$ & 12 (5 to 19$)$ & 54 (378) & $45(401)$ & $9(2$ to 16$)$ & $55(387)$ & $47(412)$ & $8(1$ to 15$)$ \\
\hline $\mathrm{MH}$ & $13(393)$ & $11(411)$ & $3(-2$ to 7$)$ & $16(380)$ & $15(404)$ & $0(-5$ to 5$)$ & $21(391)$ & $13(413)$ & 8 (3 to 14$)$ \\
\hline AOD & $15(385)$ & $13(409)$ & 2 ( -3 to 6$)$ & 20 (376) & 18 (396) & $2(-3$ to 8$)$ & $18(386)$ & $17(408)$ & 1 ( -4 to 6$)$ \\
\hline
\end{tabular}

Denominators for each percentage are shown in parentheses $(\mathrm{n})$.

ITT, intention to treat; GP, general practitioner; MH, mental health service; AOD, alcohol and other drug treatment service; IX, intervention; TAU, treatment as usual. 
Table 3 Percentage reporting health service contact at follow-up, by group (PP analyses)

\begin{tabular}{|c|c|c|c|c|c|c|c|c|c|}
\hline & \multicolumn{3}{|l|}{1 Month } & \multicolumn{3}{|l|}{3 Months } & \multicolumn{3}{|c|}{6 Months } \\
\hline & IX \% (n) & TAU \% (n) & Difference $(95 \% \mathrm{Cl})$ & IX (\%) & TAU (\%) & Difference $(95 \% \mathrm{Cl})$ & IX (\%) & TAU (\%) & Difference $(95 \% \mathrm{Cl})$ \\
\hline \multicolumn{10}{|c|}{ Service type } \\
\hline GP & $54(368)$ & $41(410)$ & 13 (6 to 20$)$ & 55 (346) & $45(401)$ & 9 (2 to 17$)$ & $58(326)$ & $47(412)$ & 10 (3 to 18$)$ \\
\hline $\mathrm{MH}$ & $13(367)$ & $11(411)$ & $2(-2$ to 7$)$ & $16(348)$ & $15(404)$ & $0(-5$ to 6$)$ & $22(330)$ & $13(413)$ & 10 (4 to 15$)$ \\
\hline$A O D$ & $15(360)$ & $13(409)$ & $1(-4$ to 6$)$ & $18(345)$ & 18 (396) & $1(-5$ to 6$)$ & $17(325)$ & $17(408)$ & $0(-5$ to 5$)$ \\
\hline
\end{tabular}

Denominators for each percentage are shown in parentheses $(\mathrm{n})$

$\mathrm{PP}$, per-protocol; GP, general practitioner; $\mathrm{MH}$, mental health service; AOD, alcohol and other drug treatment service; IX, intervention; TAU, treatment as usual.

One key limitation is reliance on self-report for the primary outcome. Although vulnerable to bias, there is growing evidence that self-report can be reliable in incarcerated populations, ${ }^{38}$ and given the single-blinded, randomised design, it is unlikely that reporting bias could explain our findings. Nevertheless, we were unable to assess whether participants had remained blinded to study condition throughout the trial, such that the possibility of response bias cannot be completely eliminated. A second limitation is that we were unable to determine the nature or outcome of health service contacts, or explore barriers to health service contact. Longitudinal studies, ideally using a mixed-methods design, would help to explicate the health-related experiences of ex-prisoners. A third limitation is that for logistical reasons, we were unable to include remand (pretrial) prisoners in our study. Given that remandees are often excluded from programmes and other support services while in custody, ${ }^{39}$ this should be a priority population for future research. A final limitation, given the substantial overrepresentation of indigenous people in Australian prisons, is that we had limited capacity to tailor the intervention and data collection tools for indigenous participants. Given evidence of particularly poor health outcomes for indigenous ex-prisoners, ${ }^{40}$ there remains an urgent need to develop and rigorously evaluate transitional interventions for incarcerated indigenous people.

\section{Conclusions}

Health outcomes after release from prison are typically poor. Under-utilisation of appropriate health services in the community may be an important driver of these poor outcomes. Our findings indicate that a brief, low-intensity intervention can have a significant and sustained impact on healthcare usage in ex-prisoners. Future studies should explore whether and under what circumstances health service usage translates into better

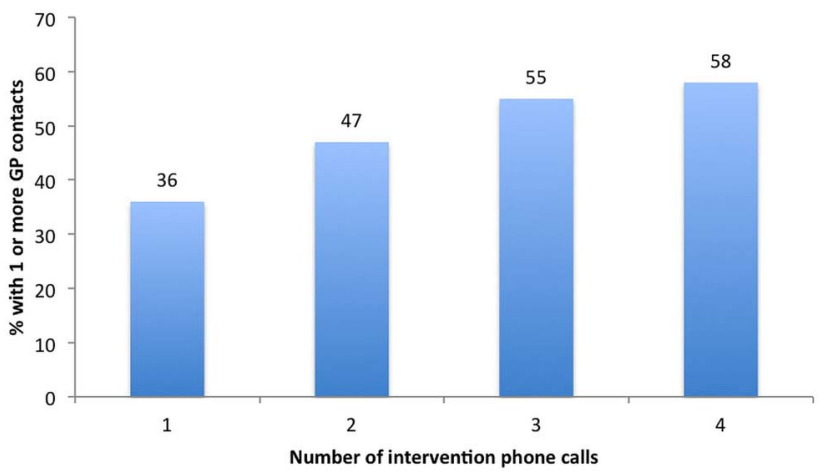

Figure 2 Percentage of intervention group participants contacting a general practitioner (GP) at 1 month post release, according to number of intervention telephone calls completed. health outcomes for ex-prisoners, and consider the costeffectiveness of interventions designed to increase healthcare usage in this population.

\section{What is already known on this subject}

We undertook a systematic review of controlled studies evaluating case management to increase health service contact in ex-prisoners, globally and with no time restrictions, using Cochrane methods. Only English language titles were retrieved. Full details of the review protocol are published elsewhere. ${ }^{18}$ We found that most studies had been undertaken in the USA with either a convenience sample or a selected, high-risk subpopulation (eg, prisoners who were HIV positive). Few studies employed a randomised design, and some suffered from poor statistical power. In most cases, case management was one component of a larger intervention. Meta-analysis was considered inappropriate due to heterogeneity in study design, intervention and outcomes measured.

\section{What this study adds}

This is the first ever randomised trial to specifically evaluate case management in ex-prisoners and the first rigorous evaluation of transitional case management outside of North America. The study is distinguished by a large, representative sample and good retention. The findings indicate that a low-intensity, brief case management intervention can have a sustained, positive impact on health service contact in ex-prisoners.

\section{Twitter Follow Stuart Kinner at @KinnerStuart}

Acknowledgements The authors wish to thank participants in the Passports project for sharing their stories, and Queensland Corrective Services for supporting the project. They wish to acknowledge the invaluable contribution to study conceptualisation and design of the late Professor Konrad Jamrozik.

Contributors SAK, NGL, RA, GMW and FMB designed the study. SAK and ML oversaw data collection. SAK produced the first draft of the manuscript. MJS undertook data analysis with advice from GMW. All authors contributed to successive drafts of the manuscript and approved the final version.

Funding The Passports project was funded by NHMRC Strategic Award \#409966. SAK is supported by NHMRC Senior Research Fellowship \#1078168. RA is supported by NHMRC Career Development Award Level 2 \#1012485.

Disclaimer The views expressed herein are solely those of the authors, and in no way reflect the views or policies of Queensland Corrective Services. 
Competing interests None declared.

Ethics approval University of Queensland Behavioural and Social Sciences Ethical Review Committee.

Provenance and peer review Not commissioned; externally peer reviewed.

Open Access This is an Open Access article distributed in accordance with the Creative Commons Attribution Non Commercial (CC BY-NC 4.0) license, which permits others to distribute, remix, adapt, build upon this work non-commercially, and license their derivative works on different terms, provided the original work is properly cited and the use is non-commercial. See: http://creativecommons.org/ licenses/by-nc/4.0/

\section{REFERENCES}

1 Walmsley R. World prison population list. 10th edn. London: International Centre for Prison Studies, Kings College, 2014.

2 Fazel S, Baillargeon J. The health of prisoners. Lancet 2011:377:956-65.

3 Herbert $\mathrm{K}$, Plugge $\mathrm{E}$, Foster $\mathrm{C}$, et al. Prevalence of risk factors for non-communicable diseases in prison populations worldwide: a systematic review. Lancet 2012;379:1975-82.

4 Glaser JB, Greifinger RB. Correctional health care: a public health opportunity. Ann Intern Med 1993;118:139-45.

5 Feron $J M$, Paulus $D$, Tonglet $R$, et al. Substantial use of primary health care by prisoners: epidemiological description and possible explanations. J Epidemiol Community Health 2005;59:651-5.

6 Kinner SA, Wang EA. The case for improving the health of ex-prisoners. Am I Public Health 2014;104:1352-5.

7 UNODC. Prevention of spread of HIV amongst vulnerable groups in South Asia. New Delhi: United Nations Office on Drugs and Crime, Regional Office for South Asia, 2008.

8 Kinner SA, Milloy M-J, Wood E, et al. Incidence and risk factors for non-fatal overdose among a cohort of recently incarcerated illicit drug users. Addict Behav 2012;37:691-6.

9 Milloy MJ, Kerr T, Buxton J, et al. Dose-response effect of incarceration events on nonadherence to HIV antiretroviral therapy among injection drug users. J Infect Dis 2011;203:1215-21.

10 Snow $K$, Young J, Preen $D$, et al. Incidence and correlates of hepatitis $C$ virus infection in a large cohort of prisoners who have injected drugs. BMC Public Health 2014; 14:830.

11 Kinner SA, Forsyth S, Williams GM. Systematic review of record linkage studies of mortality in ex-prisoners: why (good) methods matter. Addiction 2012;108:38-49.

12 Spittal MJ, Forsyth S, Pirkis J, et al. Suicide in adults released from prison in Queensland, Australia: a cohort study. I Epidemiol Community Health 2014:68:993-8.

13 Alan J, Burmas M, Preen D, et al. Inpatient hospital use in the first year after release from prison: a Western Australian population-based record linkage study. Aust N Z J Public Health 2011;35:264-9.

14 Wang EA, Wang Y, Krumholz HM. A high risk of hospitalization following release from correctional facilities in medicare beneficiaries a Retrospective Matched Cohort Study, 2002 to 2010. JAMA Intern Med 2013;173:1621-8.

15 Thomas E, Spittal M, Taxman F, et al. Health-related factors predict return to custody in a large cohort of ex-prisoners: new approaches to predicting reincarceration. Health Justice 2015:3:10.

16 Lovell D, Gagliardi GJ, Peterson PD. Recidivism and use of services among persons with mental illness after release from prison. Psychiatr Serv 2002;53:1290-8.

17 Kouyoumdjian FG, Mclsaac K, Liauw J, et al. A systematic review of randomized controlled trials of interventions to improve the health of persons during imprisonment and in the year after release. Am J Public Health 2015;105: e13-33.

18 Kinner SA, Burford BJ, van Dooren K, et al. Service brokerage interventions to improve health outcomes in ex-prisoners (protocol). Cochrane Database of Systematic Reviews 2013. doi:10.1002/14651858.CD010343

19 Wilson JA, Davis RC. Good intentions meet hard realities: an evaluation of the Project Greenlight reentry program. Criminol Public Policy 2006;5:303-38.

20 Lattimore PK, Visher CA. The multi-site evaluation of SVORI: summary and synthesis. National Institute of Justice, 2009.

21 Kinner SA, Lennox N, Williams GW, et al. Randomised controlled trial of a service brokerage intervention for ex-prisoners in Australia. Contemporary Clinical Trails 2013:36:198-206.

22 World Medical Association. World Medical Association Declaration of Helsinki: ethical principles for medical research involving human subjects. J Am Med Assoc 2013;310:2191-4.

23 Miller WR, Rollnick S. Motivational interviewing: preparing people for change. 2nd edn. New York: Guilford Press, 2002.

24 Kinner SA, van Dooren K, Boyle F, et al. Development of an intervention to increase health service utilisation in ex-prisoners. Health Justice 2014;2:4.

25 Carroll M, Kinner SA, Heffernan EB. Medication use and knowledge in a large sample of Indigenous and non-Indigenous prisoners. Aust N Z J Public Health 2014;38:142-6.

26 StataCorp. Stata Statistical Software: Release 13. College Station, TX: StataCorp LP, 2013.

27 Fazel S, Danesh J. Serious mental disorder in 23000 prisoners: a systematic review of 62 surveys. Lancet 2002;359:545-50.

28 Cutcher Z, Degenhardt L, Alati R, et al. Poor health and social outcomes for ex-prisoners with a history of mental disorder: a longitudinal study. Aust $N$ Z J Public Health 2014;38:424-9.

29 Pirkis J, Ftanou M, Williamson M, et al. Australia's Better Access initiative: an evaluation. Aust N Z J Psychiatry 2011;45:726-39.

30 Young JT, Arnold-Reed D, Preen D, et al. Early primary care physician contact and health service utilisation in a large sample of recently released ex-prisoners in Australia: prospective cohort study. BMJ Open 2015;5:e008021.

31 Fazel S, Bains P, Doll H. Substance abuse and dependence in prisoners: a systematic review. Addiction 2006;101:181-91.

32 Treloar C, Abelson J, Cao W, et al. Barriers and incentives to treatment for illicit drug users. Canberra: Australian Government Department of Health and Ageing, 2004.

33 Lawrence D, Holman CDJ, Jablensky AV. Preventable physical illness in people with mental illness. Perth: University of Western Australia, 2001.

34 Furler JS, Harris E, Chondros $\mathrm{P}$, et al. The inverse care law revisited: impact of disadvantaged location on accessing longer GP consultation times. Med J Aust 2002;177:80-3.

35 Starfield B, Shi L, Macinko J. Contribution of primary care to health systems and health. Millbank Q 2005;83:457-502.

36 Wang EA, Hong CS, Shavit S, et al. Engaging individuals recently released from prison into primary care: a randomized trial. Am J Public Health 2012;102:e22-9.

37 Cuellar AE, Cheema J. As roughly 700,000 prisoners are released annually, about half will gain health coverage and care under federal laws. Health Affairs 2012:31:931-8.

38 Schofield $\mathrm{P}$, Butler $\mathrm{T}$, Hollis $\mathrm{S}$, et al. Are prisoners reliable survey respondents? A validation of self-reported traumatic brain injury (TBI) against hospital medical records. Brain Injury 2011;25:74-82.

39 Csete J. Consequences of injustice: pre-trial detention and health. Int J Prisoner Health 2010;6:3-14.

40 Krieg AS. Aboriginal incarceration: health and social impacts. Med J Aust 2006:184:534-6. 